\title{
Challenges of Breeding Rose Rosette-resistant Roses
}

\author{
David H. Byrne', Patricia Klein, Muqing Yan, Ellen Young, and Jeekin Lau \\ Department of Horticultural Sciences, Texas A\&M University (TAMU), College Station, TX 77843
}

\begin{abstract}
Kevin Ong and Madalyn Shires
Texas Plant Disease Diagnostic Laboratory, Texas AgriLife Extension, Texas A\&M University, College Station, $T X 77843$

Jennifer Olson

Department of Entomology and Plant Pathology, Oklahoma State University (OSU), Stillwater, OK 74078

Mark Windham

Department of Entomology and Plant Pathology, The University of Tennessee, Knoxville, TN 37996
\end{abstract}

Tom Evans and Danielle Novick

Department of Plant and Soil Sciences, University of Delaware, 152 Townsend Hall, Newark, DE 19716

Additional index words. Rose rosette virus, Emaravirus, marker-assisted selection, species introgression, Rosa palustris, Rosa setigera

\begin{abstract}
Rose rosette disease (RRD) whose causal agent, the Emaravirus Rose rosette virus (RRV), was only recently identified has caused widespread death of roses in the midwestern and eastern sections of the United States. A national research team is working on the detection and best management practices for this highly damaging disease. Unfortunately, little is known about the host plant resistance to either the causal viral agent or its vector, the eriophyid mite Phyllocoptes fructiphilus. Thus far, the only confirmed resistance is among Rosa species. Of the over 600 rose cultivars observed, only $7 \%$ have not exhibited symptoms of RRD. Replicated trials are in progress to confirm resistance and/or susceptibility of $\approx 300$ rose accessions in Tennessee and Delaware. Rose is a multispecies cultivated complex that consists of diploid, triploid, and tetraploid cultivars. The basic breeding cycle is 4 years with a 3-year commercial trial coupled with mass propagation before release. Thus, if only one breeding cycle is needed, a new cultivar could be produced in 7 years. Unfortunately, for the introgression of a new trait such as disease resistance from a related species into the commercial rose germplasm, multiple generations are required which can easily take two decades from the first cross to cultivar release. Research is ongoing to develop a rapid selection procedure for resistance to RRD with the aid of molecular markers associated with the resistance. Such an approach has the potential of reducing the breeding cycle time by $50 \%$ and increasing the efficiency of seedling and parental selection manifold, leading to commercially acceptable rose cultivars with high RRD resistance in less time and with less expense.
\end{abstract}

The rose is attacked by a plethora of fungal, bacterial, and viral pathogens which cause a wide range of symptoms including leaf spotting, distortion, discoloration, and defoliation, reducing the ornamental value of these plants but usually not killing them. By contrast, RRV is currently killing large numbers of garden roses and threatening the future of the garden rose industry (Byrne et al., 2015; Windham et al., 2014, 2016). The disease complex has three important biological components: the RRV, the eriophyid mite (P. fructiphilus) vector, and the rose (Amrine, 2014; Byrne et al., 2015; Windham et al., 2014, 2016). All these vary in their

Received for publication 2 Oct. 2017. Accepted for publication 31 Oct. 2017.

This paper is part of the workshop entitled, The Challenges of Rose Rosette Disease (RRD): An Update of the Combating RRD SCRI Project, presented on 9 Aug. 2016, during the ASHS Annual conference, Atlanta, GA.

This work was partially funded by the Robert E. Basye Endowment in Rose Genetics, American Rose Society Research Endowment and the USDA's National Institute of Food and Agriculture (NIFA) Specialty Crop Research Initiative project "Combating Rose Rosette Disease: Short Term and Long Term Approaches" (2014-51181-22644/ SCRI).

${ }^{1}$ Corresponding author. E-mail: dbyrne@tamu.edu. genetics and are influenced by the environment (Fig. 1).

This virus/vector pair originated in the western part of the United States. It has spread along with Rosa multiflora, a very susceptible introduced rose species, and is now a widespread host of RRD. Thus, $R$. multiflora serves as the reservoir of inoculum and vector. In recent years, the disease has spread onto garden roses via the mite vector throughout the central and eastern United States, resulting in the death of countless rose bushes (Byrne et al., 2015; Laney et al., 2011). This has led to a reduction in the use of roses in the landscape.

The current best management practices focus on either excluding the virus or preventing its spread by managing the movement and population size of the mite vector. Thus far, the use of resistant rose cultivars in best management practices has not been incorporated as no commercial rose cultivar has been confirmed as resistant (Byrne et al., 2015; Olson and Rebek, 2015; Ong et al., 2014; Windham et al., 2016). Several decades ago, a series of rose species and a few cultivated roses were assessed for their resistance to RRD by grafting infected shoots onto test plants and observing for symptom development. Although many roses succumbed, a few species did not develop any symptoms of RRD (Amrine, 1996; Epstein and Hill, 1999; Thomas and Scott, 1953). All are species that are native to North America except for the Asian native species Rosa spinosissima (Table 1). From a breeding point of view, introgressing genetic resistance/immunity to RRD from a wild species is full of challenges. Less challenging would be to use a commercial rose, even if it was from a different horticultural class. Thus, it is important to search for a rose cultivar that is resistant to RRD.

The first step to identify RRD resistance among commercial roses was to collect observational data from trained plant pathologists, extension agents, and rosarians. The data collected were their observations on which rose cultivars developed symptoms (Fig. 2) and which ones did not develop symptoms in their gardens. Over the last 2 years, over 1100 observations have been collected from gardens in Oklahoma (Jen Olson, OSU), Texas (Kevin Ong, TAMU; Laura Miller, TAMU; Claude Graves, Rosarian; Pam Smith, Parks Director), Tennessee (Alan Windham, Mark Windham, UT), and others. These observational data based on symptomology indicate that the vast majority of garden roses are susceptible to this virusinduced disease (Table 2). Nevertheless, it should be noted that the presence of the virus was only verified in $42 \%$ of these observations, so consequently some of the roses 
Rose Rosette Disease

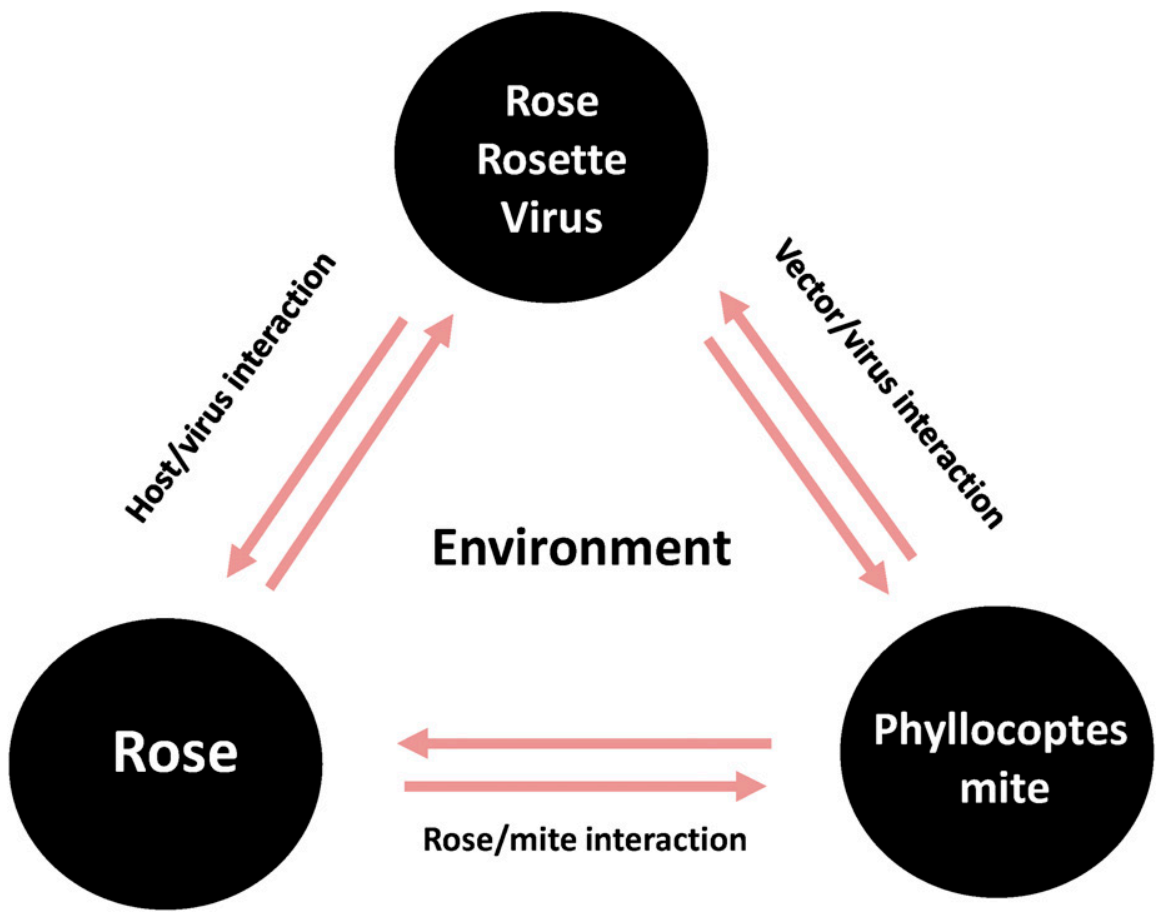

Fig. 1. Rose rosette disease complex.

Table 1. Rose sections/species reported resistant to rose rosette disease.

\begin{tabular}{lc}
\hline Diploid species & Tetraploid species \\
\hline Carolinae & Carolinae \\
Rosa palustris & Rosa carolina \\
Cinnamomeae & Cinnamomeae \\
Rosa blanda & Rosa acicularis $(4 x, 6 x, 8 x)$ \\
Rosa californica & Rosa arkansana \\
Rosa pisocarpa & \\
Systylae & Pimpinellifoliae \\
Rosa setigera & Rosa spinosissima \\
\hline
\end{tabular}

See Amrine (1995) and Epstein and Hill (1995).

identified with symptoms typical of RRD may not be susceptible to RRV but rather something else may be causing similar symptoms.

Although this approach can identify roses that have shown clear symptoms and are very likely susceptible to RRD, to prove that something is resistant, one must do a replicated trial with good disease pressure. In 2015, replicated trials to test for RRD resistance of rose cultivars and species materials were planted in Tennessee with Mark Windham (University of Tennessee) and in Delaware with Tom Evans (University of Delaware). Both these locations have high RRD pressure. To ensure uniform inoculum throughout the test block, the RRD levels are augmented by attaching miteinfested, symptomatic shoots onto the young shoots of the plants being tested for resistance. This procedure is carried out two to three times per season and the plants are checked for symptom development on a regular basis. The plants with symptoms are then checked for the presence of the virus and mites. Although few symptoms were seen on the first year of the trial, in the fall of the second year, symptoms began to appear. Combining these data with our observational data, over $90 \%$ of the roses observed appear susceptible to RRD (Table 2). Thus far, only $7 \%$ of the roses have not shown symptoms. Work is progressing to confirm the resistance of the aforementioned $7 \%$ not showing symptoms.

In parallel to these trials, all these roses are also planted in two RRD-free locations in Texas: in College Station at the TAMU Horticulture Farm with David Byrne and in Overton at the Texas AgriLife Research and Extension Center with Brent Pemberton. These are being evaluated for their susceptibility to foliar diseases (black spot, Diplocarpon rosae Wolf and cercospora, Cercospora rosicola Pass.), heat tolerance, and horticultural traits. These data will give rose breeders more information about the adaptability of the cultivars being tested.

The cultivated rose is a multispecies complex developed by intercrossing primarily 8-10 rose species with the intermittent introgression of many more. In addition, cultivated roses are mainly diploid, triploid, and tetraploid, whereas wild species range from diploid to decaploid (Jian et al., 2010; Ueckert et al., 2015; Zlesak, 2009). In general, the breeding approach in rose is phenotypic recurrent selection with the best genotypes clonally propagated (Debener and Byrne, 2014; Zlesak, 2006).
The basic breeding cycle for a garden rose consists of 1 year to create the hybrid seed, 1 year to grow and select among the seedlings in the greenhouse, and then a 2-year trial in the field to determine the selection's adaptation to the environment. Thus, it is a 4-year cycle with individuals selected in year 2 in the greenhouse for basic flower and plant characteristics as well as resistance to powdery mildew. In addition, individuals are selected in years 3 and 4 for field adaptation which includes resistance to other diseases. The best selections after the field selection are entered into a 3-year multisite commercial trial before the final decision is made on their release. Thus, it takes a minimum of 7 years to develop a new cultivar if only one breeding cycle is needed (Table 3 ).

By contrast, if a non-remontant wild species is used as a source of resistance (or other trait), the cycle becomes longer, as the first step would be to convert the wild germplasm into a remontant or recurrent blooming type. As the recurrent gene is recessive, the initial hybrids are once blooming; thus, it is not until the second cycle (produced by selfing, sibbing, or backcrossing to recurrent roses) that one can select the recurrent blooming seedlings with the trait of interest from the wild donor species. This adds a minimum of 4 years to the process which could be extended depending on issues with fertility and linkage drag. Furthermore, as species often have many traits that need to be eliminated from the final commercial cultivar, it is likely that once the germplasm has been converted into a recurrent type, another two to three cycles of breeding will be needed to develop a commercially acceptable rose cultivar with the introgressed trait. Thus, the length of such a program approaches 20 years before cultivar release This would be about twice as long as compared with using a source of the trait from a cultivated source (Table 4).

In both cases aforementioned, it would be preferable to accelerate the introgression of RRD resistance into the commercial rose germplasm. One approach to do this would be to select based on molecular markers associated with RRD resistance (Byrne, 2003; Byrne et al., 2015; Debener and Byrne, 2014).

To accomplish this goal, several tasks need to be completed.

1) A rapid genotyping format needs to be developed. Thus far, the genotyping by sequencing protocol has been optimized for diploid rose and a consensus map with 3500 SNP markers and $\approx 850$ bins has been developed. Currently, more populations and a rose germplasm collection are being genotyped.

2) Populations segregating for RRD resistance need to be developed. Roses that are thought to be resistant to RRD have been crossed with each other and with roses that are well adapted in the hot humid climate of the eastern half of 

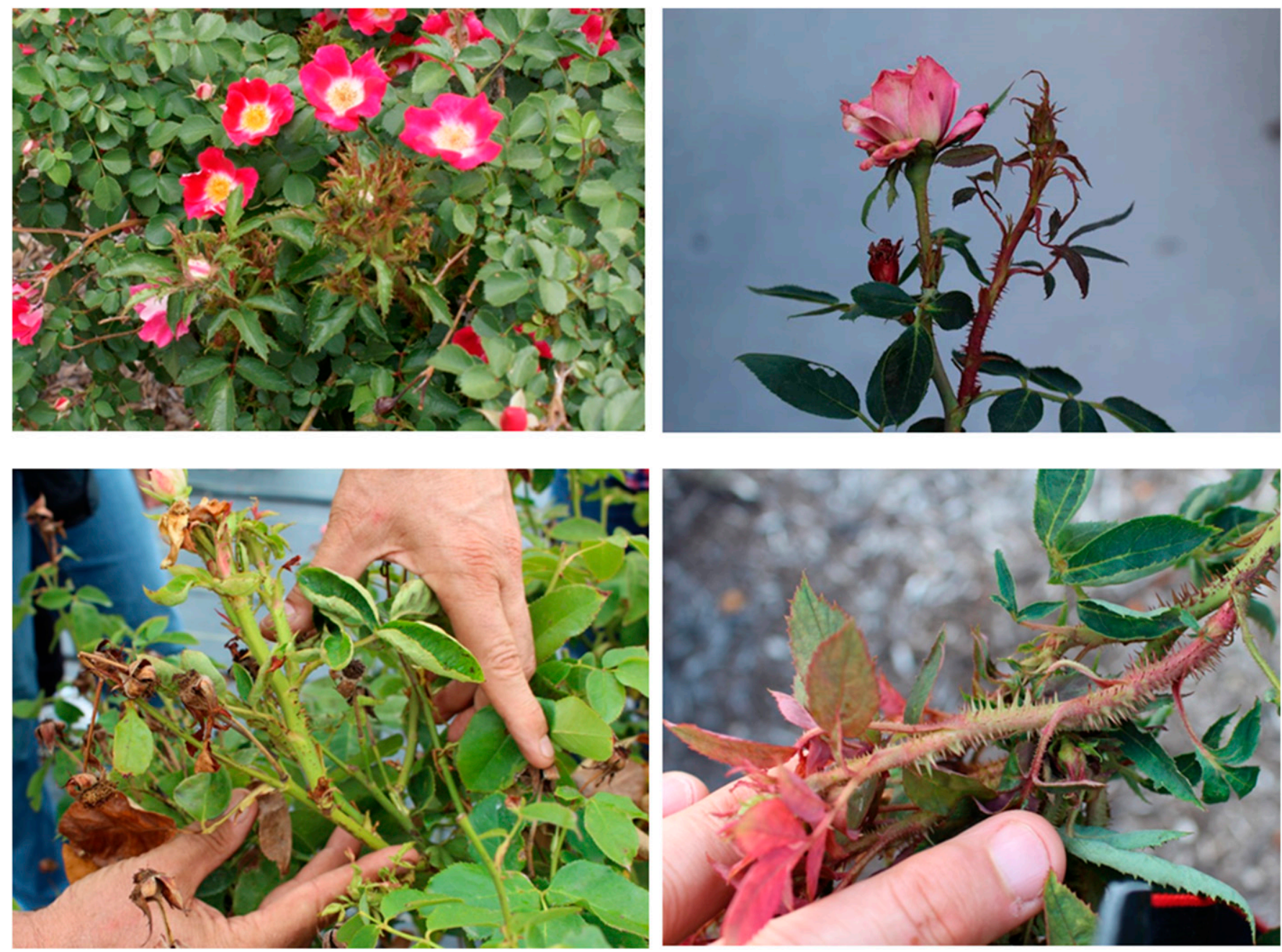

Fig. 2. Typical symptoms of rose rosette disease including the formation of a rosette, strapping of leaves, and the increased thickness and thorniness of the stems Photo courtesy of Jen Olson (Oklahoma State University), Alan Windham, Mark Windham (University of Tennessee), and David Byrne (Texas A\&M University).

Table 2. Rose cultivars observed with symptoms typical of rose rosette disease. Among the 638 roses assessed for symptoms, 268 were assayed for the Rose rosette virus.

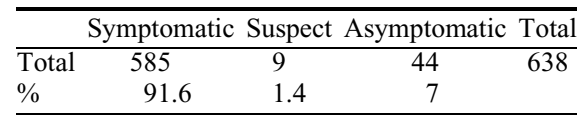

the United States where RRD is a problem. Among the putativeresistant parents, we have both species (Rosa setigera Michx., Rosa palustris Marsh., Rosa blanda Aiton, and Rosa arkansana Porter) and a commercial cultivar (Basye's Purple). As the populations become available, they are propagated to include in the field trials needed to assess their resistance to RRD.

3) Reliable phenotyping protocol is required. Currently, it takes a 2-3 year trial with replications to confirm resistance to RRD. The trials planted in 2015 will finish in 2017 . Work is progressing on other inoculation techniques to accelerate this process.
4) Analytical tools to identify markers associated with RRD resistance are needed. Traditionally, quantitative trait locus (QTL) analysis is performed on large biparental populations but, given that we have interrelated populations of 50 seedlings or less, a pedigreebased approach using the FlexQTL software to identify the markers associated with RRD resistance will be used (Bink et al., 2008, 2014; van de Weg, 2017).

The evaluation of the RRD resistance of a plant takes a minimum of 2 years in a replicated field trial. If markers could be found that are associated with RRD resistance, it would be possible to select for RRD resistance in the greenhouse without going to the field trial phase. This would shorten the breeding cycle from 4 to 2 years (Table 5). Thus, substantial time can be saved by using this technique (Table 6). Beyond giving a savings in time, the use of markers allows selection for a trait in the greenhouse and avoids the selection phase in the field which is very expensive. The selection advantage increases with the number of genes/markers that are used in the selection process. Thus, the selection for three favorable alleles in diploids and two favorable alleles in tetraploids in the context of a backcrossing program with a commercial recurrent parent that has none of these alleles would lead to a cull rate of greater than $90 \%$ per breeding cycle (Table 7). If all of these alleles are dominant, the final selections would express the traits of interest and no additional breeding for this trait(s) would be needed.

If all these favorable alleles were additive, however, further breeding would be needed after the backcrossing program to increase the dosage of these alleles to augment the expression of the trait. For a diploid rose, if only one gene was important, $25 \%$ of the progeny between heterozygous parents would be homozygous for the favorable allele. This decreases to $6.25 \%$ and $1.56 \%$ as the number of genes increases from two to three. On a tetraploid level, the backcross program would result in roses with commercial traits that have the favorable allele in the simplex state (one favorable to three unfavorable). Thus, 
Table 3. Basic breeding cycle for adapted garden roses.

\begin{tabular}{ll}
\hline Yr & Commercial elite $\times$ commercial elite \\
\hline 1 & Collect hips/stratify seed \\
& Germination \\
& Greenhouse selection for flower and plant traits, resistance to mildew \\
& Pot up selected seedlings \\
& Fall: plant in field \\
& Adaptation/horticultural assessment in field \\
$3-4$ & Commercial trial of best selections at multiple sites \\
$5-7$ &
\end{tabular}

Table 4. Time required for the release a new rose cultivar: Trait introgression from a cultivated versus a wild species source.

\begin{tabular}{|c|c|c|c|}
\hline \multicolumn{2}{|c|}{ Introgression from a cultivated source } & \multicolumn{2}{|c|}{ Introgression from a wild species } \\
\hline Cycles & $\mathrm{Yr}$ & Cycles & $\mathrm{Yr}$ \\
\hline First & $5-7$ & First (conversion) & $9-11$ \\
\hline Second & $9-11$ & Second & $13-15$ \\
\hline Third & $13-15$ & Third & $17-19$ \\
\hline Fourth & $17-19$ & Fourth & $21-23$ \\
\hline
\end{tabular}

Table 5. Timeline for developing RRD-resistant roses using DNA-informed breeding. The use of markers allows the completion of two cycles during the time needed for one cycle in the traditional approach.

\begin{tabular}{ll}
\hline Yr & \multicolumn{1}{c}{ Marker-assisted selection in the greenhouse } \\
\hline 1 & Crosses with recurrent elite and recurrent RRD-resistant parents \\
& Collect hips/stratify seed \\
& Spring: germination \\
& Greenhouse selection \\
& Flower/plant traits \\
& Resistance markers \\
& Fall: selections for pollination/field evaluation \\
& Crosses with recurrent elite and recurrent RRD-resistant parents \\
3 & Collect hips/stratify seed \\
4 & Spring: germination \\
& Greenhouse selection \\
& Flower/plant traits \\
& Resistance markers \\
& Fall: selections for pollination/field evaluation \\
\hline
\end{tabular}

$\mathrm{RRD}=$ rose rosette disease

Table 6. Timeline for the introgression of disease resistance from a cultivated versus a wild species source via traditional and marker assisted selection (MAS) for a variety release.

\begin{tabular}{|c|c|c|c|c|c|c|}
\hline \multirow[b]{2}{*}{ Cycles } & \multicolumn{3}{|c|}{ Cultivated source introgression } & \multicolumn{3}{|c|}{ Wild species source introgression } \\
\hline & $\overline{\text { Traditional }^{\mathrm{z}}}$ & $\mathrm{MAB}^{\mathrm{y}}$ & $\overline{\text { Savings (yr) }}$ & Traditional $^{\mathrm{x}}$ & $\mathrm{MAB}^{\mathrm{w}}$ & Savings (yr) \\
\hline$\overline{\text { First/conversion }}$ & 7 & 7 & 0 & 11 & 9 & 2 \\
\hline Second & 11 & 9 & 2 & 15 & 11 & 4 \\
\hline Third & 15 & 11 & 4 & 19 & 13 & 6 \\
\hline Fourth & 19 & 13 & 6 & 23 & 15 & 8 \\
\hline
\end{tabular}

$\mathrm{MAB}=$ marker-assisted breeding.

${ }^{\mathrm{z}}$ Breeding cycle is 4 years (seed production, greenhouse selection, and 2 years field selection), before release assume a 3-year multiple site commercial trial.

${ }^{\mathrm{y}}$ MAS breeding cycle is 2 years; the last cycle is 4 years as it includes a 2 -year field adaptation evaluation before the 3-year commercial trial.

${ }^{\mathrm{x}}$ Breeding cycle begins with an 8-year conversion step in which the first-generation non-recurrent hybrids are selfed, sibbed, or backcrossed to a recurrent blooming rose to get resistant gene into a recurrent blooming background; subsequent cycles take 4 years (seed production, greenhouse selection, and 2 years field selection); before release assume a 3-year multiple site commercial trial.

${ }^{\mathrm{w}}$ Breeding cycle begins with an 8 -year conversion step in which the first-generation non-recurrent hybrids are selfed, sibbed, or backcrossed to a recurrent blooming rose to get resistant gene into a recurrent blooming background. MAS breeding cycle is 2 years, the conversion process is reduced to 6 years by using MAS for resistance as selection for recurrent seedlings performed in the greenhouse, and the last cycle is 4 years as it includes a 2 -year field adaptation evaluation before the 3 -year commercial trial.

the first crosses to further increase the dosage of the favorable alleles would be between roses that have one copy of each favorable allele. This type of cross would result in duplex types but not in any roses that have three or four favorable alleles except in the case of a double reduction. The probabilities of selecting duplex types from a simplex cross, triplex types from a duplex cross, and homozygous types from a triplex cross would be similar to the diploid situation of selecting for homozygous types. The probability of the selection of homozygous types from a duplex cross is very low $(0.08 \%$ or less $)$ if multiple genes are involved, and thus, it is probably not practical (Table 8). Therefore, to fix the
Table 7. Cull rates using markers to select for a simply inherited trait ${ }^{z}$ when backcrossing to a susceptible recurrent parent with high ornamental qualities.

\begin{tabular}{lcc}
\hline No. genes & Diploid (\%) & Tetraploid $(\%)$ \\
\hline 1 & 50 & 75 \\
2 & 75 & $\approx 94$ \\
3 & $\approx 94$ & $\approx 98$ \\
\hline
\end{tabular}

${ }^{\mathrm{z}}$ Assumptions: the donor parent is heterozygous and the tetraploid parent is simplex, and there is tetrasomic segregation with random chromosome assortment. Selection is for the presence of the favorable allele(s).

favorable alleles in the breeding population (especially within tetraploids) would take several generations.

In a 15-year program to introgress a resistance gene from a species into cultivated germplasm, one can clearly see the effect of marker-assisted breeding (MAB) on seedling numbers. MAB allows for an additional selection cycle, which means an additional 10,000 seedlings can be selected in the same amount of time. Even more important is the decrease in the numbers of seedlings that need to go to the field for evaluation of resistance. This number has decreased to $14 \%$ of the number that would be planted in the field under a traditional approach. This saves substantial funds as this is an expensive phase of breeding (Table 9).

However, if the breeding program has the space and resources to continue maintaining the same size of field for the seedling evaluation, this would mean that more seedlings could be produced in each cycle (assuming sufficient greenhouse space). In fact, because only $14 \%$ of the allotted field space is used with 31,000 seedlings, the program could increase the number of initial seedlings for greenhouse selection by $\approx 700 \%$.

Finally, being able to determine the genotype rather than just the phenotype of the potential parents should improve our ability to choose the appropriate cross combinations to optimize the probability of obtaining the correct gene combination to maximize the strength of the resistance.

Rose rosette disease, caused by an Emaravirus transmitted by an eriophyid mite, is native to North America and endemic in the large expanses of $R$. multiflora populations that have naturalized in the midwest and eastern regions of the United States. Currently, although a few wild rose species have been reported resistant to the disease, no cultivated rose has been confirmed with a high level of resistance. Furthermore, little is known about the mechanism of resistance to either the virus or the mite vector. Nevertheless, it does appear that resistance to the disease exists and confirmatory replicated trials are ongoing in Tennessee and Delaware. With the markers associated with key traits, marker-assisted breeding will accelerate the breeding process. The advantages of this approach beyond reducing the length of the breeding cycle from 4 to 2 years are that it reduces the number of seedlings 
Table 8. Probability ${ }^{\mathrm{z}}$ of finding favorable alleles in one genotype when crossing individuals heterozygous for the favorable allele.

\begin{tabular}{lccccc}
\hline No. genes & Diploid (\%) & $\begin{array}{c}\text { Tetraploid (simplex to } \\
\text { duplex) (\%) }\end{array}$ & $\begin{array}{c}\text { Tetraploid (duplex } \\
\text { to triplex) (\%) }\end{array}$ & $\begin{array}{c}\text { Tetraploid (duplex to } \\
\text { homozygous) (\%) }\end{array}$ & $\begin{array}{c}\text { Tetraploid (triplex to } \\
\text { homozygous) (\%) }\end{array}$ \\
\hline 1 & 25 & 25 & 25 & 2.78 & 25 \\
2 & 6.25 & 6.25 & 6.25 & 0.08 & 6.25 \\
3 & 1.56 & 1.56 & 1.56 & 0.0021 & 1.56 \\
\hline
\end{tabular}

${ }^{\mathrm{z}}$ Assumptions: diploid heterozygous and tetraploid simplex, duplex, or triplex for favorable allele in both parents of the cross, can determine the dosage of favorable allele. Tetraploid has tetrasomic segregation with random chromosome assortment.

Table 9. The number of seedlings ${ }^{\mathrm{z}}$ screened in the greenhouse and field in the introgression of resistance to RRD from a species source in a 15 -year breeding program.

\begin{tabular}{lccc}
\hline Selection location & Traditional $^{\mathrm{y}}$ & $\mathrm{MAS}^{\mathrm{x}}$ & $\%$ of traditional program \\
\hline Greenhouse $^{\mathrm{w}}$ & 21,000 & 31,000 & 148 \\
Field & 11,105 & 1,561 & 14 \\
\hline
\end{tabular}

MAS $=$ marker-assisted selection; $\mathrm{RRD}=$ rose rosette disease.

${ }^{\mathrm{z}}$ Begins with 1000 interspecific hybrids grown in the field; 10,000 seedlings are produced for each subsequent cycle.

${ }^{y}$ An 8-year conversion phase, 4-year breeding cycle, and 3-year commercial trial.

${ }^{\mathrm{x}} \mathrm{A} 6$ 6-year conversion/MAS phase, 2 MAS cycles, 2-year field phase, and 3-year commercial trial.

${ }^{\mathrm{w}}$ Greenhouse selection, $50 \%$ eliminated for flower/plant traits and if MAS $90 \%$ for resistance markers.

that needs to be planted in the field and that it allows the selection of parents with the desired gene(s), not just with the desired phenotype, as a single phenotype may be conditioned by several combination of genes.

\section{Literature Cited}

Amrine, J.W. 1996. Phyllocoptes fructiphilus and biological control of multiflora rose, p. 741749. In: E.E. Lindquist, M.W. Sabelis, and J. Bruins (eds.). Eriophyid mites-Their biology, natural enemies and control. Elsevier, Amsterdam, The Netherlands.

Amrine, J.W. 2014. What happens to Phyllocoptes fructiphilus the vector of Rose rosette virus in the winter? Amer. Rose Annu. 42:118-121.

Amrine, J.W., A. Kassar, and T.A. Stasny. 1995. Phyllocoptes fructiphilus K. (Acari: Eriophyoidea), the vector of Rose Rosette disease, taxonomy, biology and distribution, p. 61-66. In: Rose Rosette and Other Eriophyid Mitetransmitted Plant Disease Agents of Uncertain Etiology, May 19-21, 1994, Iowa State Univ.

Bink, M.C., M.P. Boer, C.J. ter Braak, H. Jansen, R.E. Voorrips, and W.E. van de Weg. 2008. Bayesian analysis of complex traits in pedigreed plant populations. Euphytica 161:85-96.

Bink, M.C.A.M., J. Jansen, M. Madduri, R.E. Voorrips, C-E. Dure1, A.B. Kouassi, F. Laurens, F. Mathis, C. Gessler, D. Gobbin,
F. Rezzonico, A. Patocchi, M. Kellerhals, A. Boudichevskaia, F. Dunemann, A. Peil, A. Nowicka, B. Lata, M. Stankiewicz-Kosyl, K. Jeziorek, E. Pitera, A. Soska, K. Tomala, K.M. Evans, F. Fernández-Fernández, W. Guerra, M. Korbin, S. Keller, M. Lewandowski, W. Plocharski, K. Rutkowski, E. Zurawicz, F. Costa, S. Sansavini, S. Tartarini, M. Komjanc, D. Mott, A. Antofie, M. Lateur, A. Rondia, L. Gianfranceschi, and W.E. van de Weg. 2014. Bayesian QTL analyses using pedigreed families of an outcrossing species, with application to fruit firmness in apple. Theor. Appl. Genet. 127: 1073-1090.

Byrne, D.H. 2003. Marker-assisted selection, p. 350-357. In: A.V. Roberts, T. Debener, and S. Gudin (eds.). Encyclopedia of rose science. Elsevier, Amsterdam, The Netherlands.

Byrne, D.H., E. Roundey, P. Klein, and M. Yan. 2015. Combating rose rosette disease: Are there resistant roses? Amer. Rose 43(5):7883.

Debener, T. and D.H. Byrne. 2014. Disease resistance breeding in rose: Current status and potential of biotechnological tools. Plant Sci. 228:107-117.

Epstein, A.H. and J.H. Hill. 1995. The biology of rose rosette disease: A mite-associated disease of uncertain aetiology, J. Phytopathol. 143:353360 .
Epstein, A.H. and J.H. Hill. 1999. Status of rose rosette disease as a biological control for multiflora rose. Plant Dis. 83(2):92-101.

Jian, H., H. Zhang, K. Tang, S. Li, Q. Wang, T. Zhang, X. Qiu, and H. Yan. 2010. Decaploidy in Rosa praelucens byhouwer (Rosaceae) endemic to Zhongdian Plateau, Yunnan, China. Caryologica 63:162-167.

Laney, G., K.E. Keller, R.R. Martin, and I.E. Tzanetakis. 2011. A discovery 70 years in the making: Characterization of the Rose rosette virus. J. Gen. Virol. 92:1727-1732.

Olson, J. and E. Rebek. 2015. Rose rosette disease. Oklahoma Coop. Ext. Serv., EPP-7329. 10 July 2015. <http://pods.dasnr.okstate.edu/docushare/ dsweb/Get/Document-9207/EPP-7329web.pdf $>$.

Ong, K., M. Giesbrecht, D. Woodson, and L. Miller. 2014. Rose rosette disease demystified. Texas AgriLife Ext. EPLP-010.

Thomas, E.A. and C.E. Scott. 1953. Rosette of rose. Phytopathology 43:218-219.

Ueckert, J., D.H. Byrne, K. Crosby, G. Hodnett, and D. Stelly. 2015. The utilization of the polyploid nature of roses. Acta Hort. 1064: 73-78.

van de Weg, W.E. 2017. FlexQTL ${ }^{\mathrm{TM}}$ - Quantitative genetics on pedigreed populations. 10 June 2017. <http://www.wur.nl/en/show/FlexQTL. htm>.

Windham, M., A. Windham, and F. Hale. 2016 Managing rose rosette in the landscape-Ideas based on experimental data. Amer. Rose 44:36-38.

Windham, M., A. Windham, F. Hale, and J. Amrine. 2014. Observations on rose rosette disease. Amer. Rose 42:56-62.

Zlesak, D. 2006. Rose. Rosa $\times$ hybrida, p. 695-738 In: N.O. Anderson (ed.). Flower breeding and genetics. Springer, The Netherlands.

Zlesak, D.C. 2009. Pollen diameter and guard cell length as predictors of ploidy in diverse rose cultivars, species, and breeding lines. Flori. Orn. Biotechnol. 3(Special Issue 1): 53-70. 